\title{
Hazelnut phenological phases and environmental effects in two central Italy areas
}

\author{
Fabio OrLANDI ${ }^{\dagger}$, Aldo Ranfa, Luigia Ruga and Marco Fornaciari \\ ( Department of Civil and Environmental Engineering, University of Perugia, Borgo XX Giugno 74, 06121 Perugia, Italy )
}

\begin{abstract}
Hazelnut trees, were investigated in central Italy to study their biology and relationships with principal environmental variables. The cyclical repetition of seasonal development in plants may be sensitive to meteorological variation, making phenology of particular interest for studying the climate change effects on vegetative development using new standardization techniques for observing and interpreting the growth of different plant species. Plants of Corylus avellana L. planted in phenological gardens in central Italy areas were examined to analyse the phenology of their growth stages in relation to different climate characteristics. Phenological observations following the guidelines of the International Phenological Gardens network were carried out during a 13-year period. Temperature and solar radiation showed the highest homogeneity among the different vegetative phases in both of the study areas, while other meteorological variables (Precipitation and RH) were heterogeneous also considering the particular water table levels present in one of the two observation areas. Two periods ("first leaf development" (FLD) and "leaf presence period" (LPP)) were considered to study the influence of meteorological variables on plant development during important vegetative periods. A certain shortening of the first period was attributed to the delay in bud swelling beginning during the study period. In contrast, a lengthening of the LPP, was related to the progressive delay in the senescence phase.
\end{abstract}

Key words: Climate, Hazelnut, Phenological stages

\section{Introduction}

The observations of vegetative and reproductive phenology recorded during the annual ontogenetic cycle of different plant species permit the interpretation of the relationships between environmental factors and natural vegetation consisting of spontaneous and agricultural plants (Chmielewski et al., 2004; Menzel et al., 2006; Orlandi et al., 2007; Waldau and Chmielewski, 2018). In the last few decades, agro-phenology has been limited mostly to cereals and other herbaceous species and has considered phenology fundamental for crop management, such as pest control, irrigation, and spraying against diseases.

Generally, the principal recurrences of seasonal climatic features and annual meteorological anomalies may be reflected in plant phenological development (Aguilera et al., 2014; Bergant et al., 2002; Chuine et al., 2010; Gordo and Sanz, 2010; Kramer, 1994; Schleip et al., 2008). In deciduous tree crops, the dates of flowering and leafing at the end of winter/in early spring are conditioned by the chilling requirements of buds and the successive heat requirement (after dormancy break) as an adaptation for preventing the beginning of vegetative development before frosts occurring during February-March, which may be very dangerous in Mediterranean areas (Larcher, 2003).

The purpose of this study was to determine and analyse the phenological vegetative growth stages of some clonal trees of hazelnut (Corylus avellana L. cv. 'Tonda gentile delle Langhe') in relation to climate characteristics recorded in two phenological gardens in central Italy included in the International

\footnotetext{
Received; September 15, 2018

Accepted; March 6, 2019

†Corresponding Author: fabio.orlandi@unipg.it

DOI: 10.2480/agrmet.D-18-00036
}

Phenological Gardens (IPG) network and thus not subjected to invasive agronomic techniques. The oldest phenological garden, located near Perugia, central Italy, contains data since 1997 for some indicator species common to the IPG network (Orlandi et al., 2007; Schnelle and Volkert, 1964) that were originally obtained from mother plants received from the German Weather Service, the European coordinator of the distribution of IPG clones. The more recent garden is located in Rieti and contains the same clonal species, with observations occurring from 2005 to the present.

Usually, a "national section" is also present in the gardens, where widely distributed plants of economic interest due to their cultivation are planted. In the two considered gardens, olive (Olea europaea L.) trees of different cultivars are present, similar to hazelnut, as these two species are economically important for Italy (the country is the second largest global producer of olive fruits after Spain and the second largest global producer of hazelnut fruits after Turkey).

The principal aim of this study was to determine the relationships between the main meteorological variables and the vegetative development of hazelnut trees during a 13 -year period (2005-2017) while also monitoring current climatic changes and observing potential adaptations of the trees based on phenological variations during the different growing seasons.

\section{Materials and methods}

\subsection{The phenological gardens}

The gardens planted in central Italy in 1990 have always operated in accordance with the common guidelines established decades ago by the pioneer phenological gardens in central Europe (Orlandi et al., 2007, 2014; Schnelle and Volkert, 1964). The first phenological garden considered here is one of the oldest ones in Italy and includes local, national and some indicator 
species common to all IPGs. It is located $15 \mathrm{~km}$ from Perugia (Umbria Region, central Italy) in an area with a Mediterranean climate with a subcontinental influence. The garden has the following geographical coordinates: $43^{\circ} 00^{\prime} 40^{\prime \prime} \mathrm{N}$ latitude and $12^{\circ} 14^{\prime} 52^{\prime \prime} \mathrm{E}$ longitude, and its total area is approximately $4,000 \mathrm{~m}^{2}$.

The second phenological garden considered here is located in the Rieti plain (Lazio Region, central Italy). This garden (lat: N 42 25'30"; long: E 1249'45"; alt.: approximately $270 \mathrm{~m}$ a.s.1.) has an area of approximately $2,000 \mathrm{~m}^{2}$ and is located $5 \mathrm{~km}$ from Rieti. The vegetative species in this garden were planted more recently (starting in 2005) than those in the first garden.

In both the gardens, since the first cultivation period, 5 hazelnut trees (cv. 'Tonda gentile delle Langhe') were planted due to the widespread cultivation of this cultivar in the north-central hazelnut orchards of the country.

\subsection{Meteorological data}

The meteorological data for both phenological gardens were obtained directly from meteorological stations located near the gardens. In the Rieti plain, the meteorological station is managed by the "Apennines Centre of Terminillo Mt." of the University of Perugia (http://www.cat.unipg.it). The meteorological data for the Perugia garden were obtained from the station of the Italian Agrometeorological Network (http://cma.entecra.it/homePage_EN.htm) located approximately $100 \mathrm{~m}$ from the phenological garden. The variables considered were temperature $\left({ }^{\circ} \mathrm{C}\right.$, maximum and minimum), precipitation $(\mathrm{mm})$, relative humidity $(\%)$, and solar radiation $\left(\mathrm{KJ} / \mathrm{m}^{2}\right)$. The daily data for the 13-year period (2005-2017) were averaged to obtain weekly values.

\subsection{Phenological methodology}

Every phenological stage represents a precise biological event, and to obtain comparable values from the observations made in International Phenological Gardens, the Biologische Bundesanstalt, Bundessortenamt, Chemische Industrie (BBCH) phenological keys were used, as described by various authors (Chmielewski and Rötzer, 2001; Saska and Kuzovkina, 2010). In particular, in the present study, the following phenological phases were considered for the vegetative cycle of hazelnut trees: $\mathrm{BBCH} 02$, beginning of bud swelling; $\mathrm{BBCH} 11$, first true leaf; and $\mathrm{BBCH} 95$, leaves have mostly fallen $(50 \%$ of leaves have fallen). Also $\mathrm{BBCH} 65$ (full flowering) was reported to evidence reproductive developments during the study period.

In each garden, observations were conducted on three individuals of the five hazelnut trees (in accordance with directives to replace any failures) to limit random variability, and the mean date of the onset of each phenophase was calculated as an average of the three plants.

Two principal periods, namely, "first leaf development-FLD" and "leaf presence period-LPP", were considered and evaluated during the study years in the two areas. FLD was calculated as the number of weeks between BBCH 02 and $\mathrm{BBCH}$ 11, while LPP was calculated as the number of weeks between $\mathrm{BBCH} 11$ and 95 .

\subsection{Relationships between meteorological requirements and the phenological phases}

On the basis of the principal objective of the phenological gardens in different cultivation areas and to evaluate the phenological development in various climatic regions, the weekly sums of the principal meteorological variables (TMax, Tmin, Rain, RH, and Sol.Rad) were calculated for each year to all the phenological phases dates. Statistical analyses of the relationships between the phenological dates, the period calculated (FLD-LPP) and the meteorological variables during the 13 years of the study were performed.

Correlation analyses were performed considering the same phenological dates and the weekly values of the principal meteorological variables. Moreover, a trend analysis was done using non parametric Mann-Kendall tests for monotonic positive or negative trends, considering the phenological small samples available (13-year data in both the 2 observation areas) and their distribution not really adjustable to normal distribution for which this test is particularly adaptable (Pohlert, 2015). The not normal distribution of phenological data were verified with the Shapiro-Wilk and Anderson-Darling tests. The phenological values showed not normal distribution (rejection of null hypothesis) in both studied areas at least for one considered test, setting us toward the use of Mann-Kendall non-parametric statistic test that sign of the difference between later-measured data and earlier-measured data. Each later-measured value is compared to all values measured earlier, resulting in a total of $n(n-1) / 2$ possible pairs of data, where $\mathrm{n}$ is the total number of observations (Meals et al., 2011). To test for the presence of trends in the meteorological data, the weekly sums of TMax, Tmin, Rain, RH, and Sol.Rad were calculated from the January 1 st to the phenological phases dates and during the calculated phenological periods (FLD-LPP). Finally, trend analysis was also performed for the weekly sums of the meteorological variables (positive $Z$, increased; negative $Z$, decreased) to the phenological dates for both the phenological gardens. To estimate the true slope of an existing trend (as change per year), Sen's nonparametric method was used (Sirois, 1998). For the significance levels, the following symbols are used: + , trend at $p<0.05 ; *$, trend at $p<0.01$; and $* *$, trend at $p<0.001$.

\section{Results}

In Fig. 1 the Box Plots with the reproductive and vegetative phenological dates for Hazelnut in both the study areas are reported. Full flowering (Fig. $1 \mathrm{~A}$ ) was recorded during the first weeks of the years, in Perugia the median value is recorded in the 7th week while in Rieti one week later. Moreover, in Perugia the reproductive phenomenon is distributed more regularly around median in comparison to the variability of Rieti. In Fig. $1 \mathrm{~B}$ also the first vegetative phase ( $\mathrm{BBCH} 02)$, recorded only few weeks later, manifest the same behaviours with a more homogeneous dates distribution in Perugia (with the exception of one outlier value) respect Rieti. $\mathrm{BBCH} 11$ shows the same median value (during the 14th week) in both the gardens with quite the same distribution during the study period. The fallen leaves dates (BBCH 95) presented in Fig. 1C, evidenced an advance in Perugia where the median was recorded in the 39th 


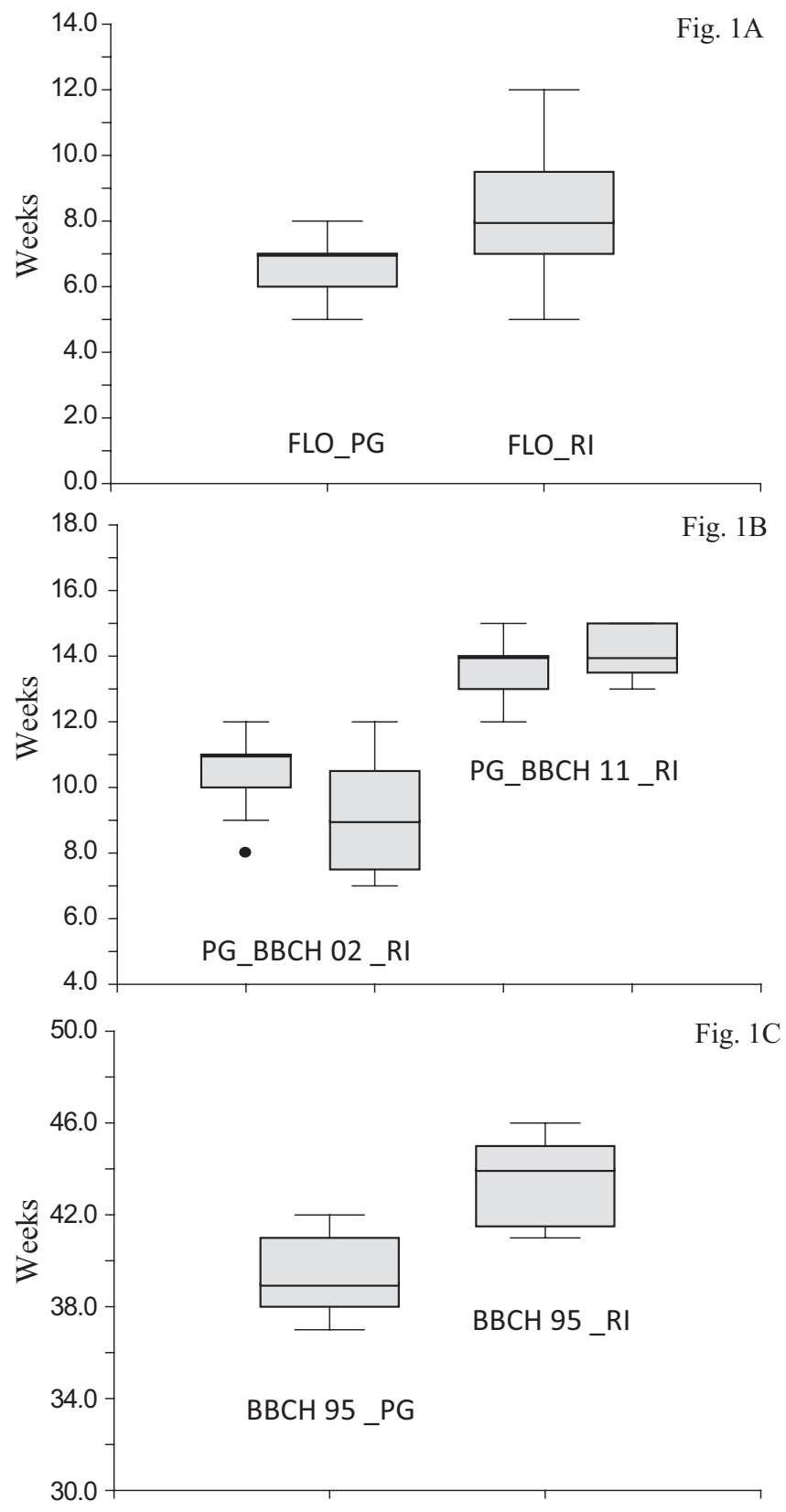

Fig. 1. Box Plot of phenological dates recorded in the gardens of Perugia (PG) and Rieti (RI). Flowering (FLO); BBCH 02-11 and 95.

week respect to Rieti (44th week).

The statistical results reported in Table 1 present the trend analyses of all the vegetative phenological phases and correlation between them and the elaborated periods (FLD, LPP). Beginning of bud swelling (BBCH02) present significant positive trends in both the areas manifesting the progressive tendency of this phenomenon to be recorded more and more later. First true leaf (BBCH11) not presented any significant trends, while mostly fallen leaves (BBCH95) only in Rieti show an highly significant positive trend due to the progressive delay of the plant senescence.

The correlation analyses show the high relationships between $\mathrm{BBCH} 02$ and FLD in both areas, the negative correlation value indicate that to $\mathrm{BBCH}$ delay (value increase) correspond FLD shortening and vice versa. Moreover, high correlation values may be evidenced between LPP and BBCH 95, plant senescence delay induce the LPP lengthening.

The statistical results reported in Table 2 permit to evidence as flowering, although showing an advance during the observation years, shows no significant trend in both gardens (Test Z -1.27 in Perugia and -1.37 in Rieti). The correlation values between Flowering phase and environmental variables, recorded from January 1st and yearly BBCH 65 dates, show a high influence of TMax, Sol.Rad and HR in both the study areas. As regard the Rain, a different behaviour can be observed in the 2 gardens, in Rieti, flowering is less conditioned by precipitation in comparison to HR while in Perugia rain is significantly related. Moreover, also the relationships between Rain and HR are heterogeneous in the two areas, in Perugia these variables are highly related while in Rieti probably HR depends also by other 
Table 1. Trend analyses of all the vegetative phenological phases $(\mathrm{BBCH} 02 ; 11 ; 95)$ and correlation between them and the elaborated periods (FLD, LPP), in both gardens ( $\mathrm{PG}=$ Perugia; $\mathrm{RI}=$ Rieti)

\begin{tabular}{|c|c|c|c|c|c|}
\hline \multicolumn{3}{|c|}{ Mann-Kendall trend } & \multicolumn{3}{|c|}{$\begin{array}{c}\text { Correlation } \\
(* p<0.05 ; * * p<0.01)\end{array}$} \\
\hline Series & Test Z & Sig. & & PG FLD & RI FLD \\
\hline PG BBCH 02 & 1.95 & + & ВBCH 02 & $-0.80 * *$ & $-0.88 * *$ \\
\hline PG BBCH 11 & -1.35 & & BBCH 11 & 0.54 & 0.12 \\
\hline PG BBCH 95 & 0.06 & & & & \\
\hline RI BBCH 02 & 2.38 & $*$ & & PG LPP & RI LPP \\
\hline RI BBCH 11 & 0.46 & & ВBCH 11 & -0.25 & -0.31 \\
\hline RI BBCH 95 & 2.24 & $*$ & BBCH 95 & $0.87 * *$ & $0.90 * *$ \\
\hline
\end{tabular}

environmental aspects.

The FLD period trends presented in Table 2 show significant negative values in both areas suggesting as during the 13-year this elaborated phenological period has gradually decreased. In addition, Sol.Rad and Rain present the same significant decreasing trends while only in Rieti Tmin joins the previous two environmental variables. Correlation analyses show high relationships between FLD and all the environmental variables while in Rieti area Tmin and Rain present not significant values. In particular, in Rieti the low correlation between HR values and Rain is confirmed.

The LPP elaborated period presented in Table 2 show a significant positive trend only in the Rieti area suggesting the progressive lengthening of the period. In Rieti, also Sol.Rad show a significant trend but negative (due to the progressive

Table 2. Trend analyses and correlation tests in both gardens $(P G=$ Perugia; $R I=$ Rieti $)$ between Flowering phase, FLD, LPP periods and meteorological variables recorded from January 1 st.

\begin{tabular}{|c|c|c|c|c|c|c|c|c|c|}
\hline \multicolumn{3}{|c|}{ Mann-Kendall trend } & \multicolumn{7}{|c|}{ Correlation $(* p<0.05 ; * * p<0.01)$} \\
\hline Series & Test Z & Sig. & & PG FLO & TMAX & TMIN & Sol.Rad & RAIN & HR \\
\hline PG FLO & -1.27 & & PG FLO & 1.00 & & & & & \\
\hline TMAX & -1.07 & & TMAX & $0.73 *$ & 1.00 & & & & \\
\hline Tmin & 1.07 & & TMIN & -0.16 & 0.51 & 1.00 & & & \\
\hline Sol.Rad & -2.86 & $* *$ & Sol.Rad & $0.75^{*}$ & 0.27 & -0.56 & 1.00 & & \\
\hline RAIN & -0.54 & & RAIN & $0.65^{*}$ & $0.92 * *$ & 0.56 & 0.15 & 1.00 & \\
\hline HR & -1.43 & & HR & $0.84 * *$ & $0.95 * *$ & 0.36 & 0.44 & $0.94 * *$ & 1.00 \\
\hline RI FLO & -1.37 & & RI FLO & 1.00 & & & & & \\
\hline TMAX & -1.61 & & TMAX & $0.96^{* *}$ & 1.00 & & & & \\
\hline Tmin & 0.00 & & TMIN & -0.45 & -0.32 & 1.00 & & & \\
\hline Sol.Rad & -1.79 & + & Sol.Rad & $0.94 * *$ & $0.92 * *$ & -0.55 & 1.00 & & \\
\hline RAIN & -0.72 & & RAIN & 0.37 & 0.37 & 0.48 & 0.13 & 1.00 & \\
\hline HR & -1.43 & & HR & $0.98 * *$ & $0.95^{* *}$ & -0.31 & $0.89 * *$ & 0.51 & 1.00 \\
\hline PG FLD & -2.07 & $*$ & PG FLD & 1.00 & & & & & \\
\hline TMAX & -1.65 & + & TMAX & $0.86^{* *}$ & 1.00 & & & & \\
\hline TMIN & -1.37 & & TMIN & $0.60^{*}$ & $0.80 * *$ & 1.00 & & & \\
\hline Sol.Rad & -2.01 & $*$ & Sol.Rad & $0.89 * *$ & $0.92 * *$ & $0.72 *$ & 1.00 & & \\
\hline RAIN & -1.77 & + & RAIN & $0.86^{* *}$ & 0.55 & 0.32 & $0.69^{*}$ & 1.00 & \\
\hline HR & -1.40 & & HR & $0.98 * *$ & $0.86^{* *}$ & $0.62 *$ & $0.86^{* *}$ & $0.82 * *$ & 1.00 \\
\hline RI FLD & -2.29 & $*$ & RI FLD & 1.00 & & & & & \\
\hline TMAX & -1.24 & & TMAX & $0.92 * *$ & 1.00 & & & & \\
\hline TMIN & -1.89 & + & TMIN & 0.32 & 0.26 & 1.00 & & & \\
\hline Sol.Rad & -2.01 & $*$ & Sol.Rad & $0.90 * *$ & $0.92 * *$ & 0.12 & 1.00 & & \\
\hline RAIN & -2.57 & $*$ & RAIN & 0.42 & 0.32 & $0.66^{*}$ & 0.40 & 1.00 & \\
\hline HR & -1.16 & & HR & $0.94 * *$ & $0.91 * *$ & 0.37 & $0.88 * *$ & 0.53 & 1.00 \\
\hline PG LPP & 0.44 & & PG LPP & 1.00 & & & & & \\
\hline TMAX & 0.43 & & TMAX & $0.89 * *$ & 1.00 & & & & \\
\hline TMIN & 1.16 & & TMIN & $0.85^{* *}$ & $0.88 * *$ & 1.00 & & & \\
\hline Sol.Rad & -2.62 & $* *$ & Sol.Rad & 0.17 & 0.22 & -0.15 & 1.00 & & \\
\hline RAIN & -0.43 & & RAIN & 0.38 & 0.07 & 0.21 & -0.05 & 1.00 & \\
\hline HR & 0.31 & & HR & $0.81 * *$ & $0.59 *$ & $0.75 *$ & -0.24 & $0.67 *$ & 1.00 \\
\hline RI LPP & 2.00 & $*$ & RI LPP & 1.00 & & & & & \\
\hline TMAX & 1.53 & & TMAX & 0.56 & 1.00 & & & & \\
\hline TMIN & 1.40 & & TMIN & 0.40 & $0.88^{* *}$ & 1.00 & & & \\
\hline Sol.Rad & -2.50 & $*$ & Sol.Rad & $-0.61^{*}$ & -0.21 & -0.26 & 1.00 & & \\
\hline RAIN & 0.31 & & RAIN & 0.20 & $0.69^{*}$ & $0.88 * *$ & -0.02 & 1.00 & \\
\hline HR & -0.06 & & HR & 0.41 & $0.58^{*}$ & $0.57 *$ & -0.09 & $0.78^{*}$ & 1.00 \\
\hline
\end{tabular}


F. Orlandi et al. : Hazelnut phenology in central Italy

Table 3. Statistical relationships (trend and correlation tests) between the beginning of bud swelling (BBCH 02) and meteorological variables in both gardens $(\mathrm{PG}=$ Perugia; $\mathrm{RI}=$ Rieti $)$.

\begin{tabular}{|c|c|c|c|c|c|c|c|c|c|}
\hline \multicolumn{3}{|c|}{ Mann-Kendall trend } & \multicolumn{7}{|c|}{ Correlation $(* p<0.05 ; * * p<0.01)$} \\
\hline Series & Test Z & Sig. & & PG 02 & TMAX & TMIN & Sol.Rad & RAIN & HR \\
\hline PG BBCH 02 & 1.95 & + & PG BBCH 02 & 1 & & & & & \\
\hline TMAX & 2.99 & $* *$ & TMAX & $0.80 * *$ & 1 & & & & \\
\hline Tmin & 2.01 & $*$ & TMIN & 0.16 & 0.55 & 1 & & & \\
\hline Sol.Rad & 0.18 & & Sol.Rad & 0.55 & 0.26 & -0.54 & 1 & & \\
\hline RAIN & -0.06 & & RAIN & -0.56 & -0.42 & 0.26 & -0.58 & 1 & \\
\hline HR & 2.01 & $*$ & HR & $0.63 *$ & 0.54 & $0.63 *$ & -0.05 & -0.03 & 1 \\
\hline RI BBCH 02 & 2.38 & $*$ & RI FLO & 1 & & & & & \\
\hline TMAX & 2.15 & $*$ & TMAX & $0.91 * *$ & 1 & & & & \\
\hline Tmin & 0.00 & & TMIN & -0.39 & -0.17 & 1 & & & \\
\hline Sol.Rad & 0.36 & & Sol.Rad & $0.85^{* *}$ & $0.76^{*}$ & $-0.68^{*}$ & 1 & & \\
\hline RAIN & 0.36 & & RAIN & 0.26 & 0.24 & $0.64 *$ & -0.12 & 1 & \\
\hline HR & 1.79 & + & HR & $0.94 * *$ & $0.88^{* *}$ & -0.09 & $0.67 *$ & 0.55 & 1 \\
\hline
\end{tabular}

decrease of its yearly values) and a significant negative correlation with LPP (Sol.Rad decrease induce a BBCH95 delay and consequently ever more longer LPP). In Perugia, high correlation values have been recorded between LPP, temperatures and $\mathrm{HR}$.

Considering that $\mathrm{BBCH} 02$ was the phenological phase which showed the principal trends in both areas Table 3 present statistical relationships between the beginning of bud swelling and meteorological variables. TMax, HR and Sol.Rad showed the highest correlation values in the 2 areas. Both the temperature and HR showed significant positive (increasing) trends in Perugia while in Rieti only TMax and HR.

Figure 2 shows the trend analysis of the more significant hazelnut phenological phases in the two gardens. In both study areas, phase $\mathrm{BBCH02}$ showed a significant increasing trend corresponding to a progressive delay in the beginning of bud swelling, while $\mathrm{BBCH} 95$ exhibited the same significant tendency only in Rieti. The meteorological variables showed the same trends in the two gardens, with increasing and decreasing tendencies in relation to the amount of solar radiation before the beginning of bud swelling. Only in Rieti, the solar radiation amounts calculated between the first true leaf and leaf fall dates decreased progressively during the 13 -year period, showing a significant negative coefficient $\left(Z=-2.44^{*}\right)$.

\section{Discussion and conclusion}

The flowering of the observed Hazelnut trees evidenced a progressive, but not significant, advance during the considered series of the years. The unique meteorological variable with a significant trend in both areas was Solar radiation which manifested a progressive reduction but apparently not able to influence the major reproductive phenomenon (probably mostly linked to local photoperiod).

As regard the Rain, a different behaviour can be observed in the 2 gardens. In Rieti, flowering is less conditioned by precipitation in comparison to HR while in Perugia rain is significantly related. Moreover, also the relationships between Rain and HR are heterogeneous in the two areas, in Perugia these variables are highly related while in Rieti probably HR depends also by other environmental aspects.

In particular, the water table level in the Rieti area, relatively near to the surface, can provoke easily flooding phenomena during winter, Rieti plain is inserted in the hydrographic basin of the Velino river characterized by the presence of a ground water at the depth of 1.5-2.0 m for most of the growing season which highly influence HR levels.

Moreover, the correlation analyses show high relationships between FLD and all the environmental variables while in Rieti area Tmin and Rain present not significant values. In particular, in Rieti the low correlation between HR values and Rain is confirmed.

The statistical results revealed a significant decreasing trend in solar radiation during the study period probably linked to the similarly significant progressive bud swelling and fallen leaves (in Rieti) delay, FLD shortening and LPP lengthening.

In particular, on the basis of the obtained results, the progressive FLD shortening in both the study areas can likely be attributed to the progressive delay in the beginning of bud swelling $(\mathrm{BBCH}$ 02) and the simultaneously lack of change in the first true leaf dates (BBCH 11) across the years. The influence of temperature (although with low significant levels) but also of Rain and Sol. Rad practically permitted the young leaves to develop over shorter periods and reach complete development $(\mathrm{BBCH} 11)$ in the same weeks during the study period.

In contrast, the trends of the LPP period in both the areas were probably influenced by the variation in $\mathrm{BBCH} 95$ dates. In this sense, the lengthening of the LPP period in Rieti may be related to the progressive delay in the senescence phase across the years, as the $\mathrm{BBCH} 95$ moved from an average of the 43rd week to an average of the 45 th week during the last observation years.

By a physiological point of view the combined statistical analyses may suggest as the closed buds, protected and insulated by the perulae, were more influenced by trends in solar radiation than by trends in temperature. In this sense, the statistical results carried out by considering $\mathrm{BBCH} 02$ dates in progressive delay during the observation period and the corresponding meteorological variables sums year by year may confirm this hypothesis. The trend analysis evidenced as temperature and HR 

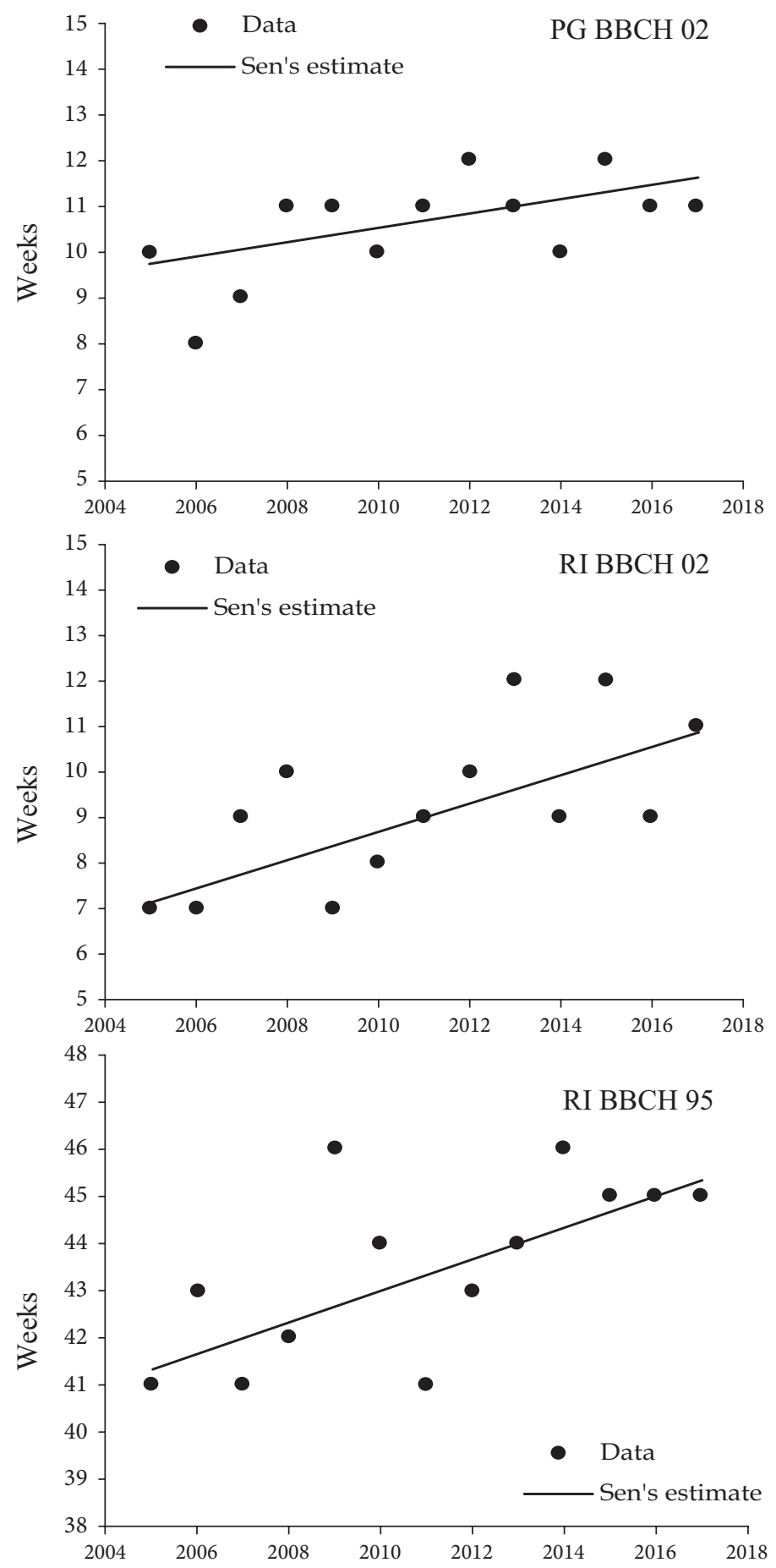

Fig. 2. Trend analysis of the more significant hazelnut phenological phases (BBCH 02-95) in the two gardens.

summations increased in both areas according to the progressive vegetative delay while rain and solar radiation not presented significant trends recording constant amounts in increasingly weeks (linked to the local Sol.Rad decreasing phenomenon).

Successively, after bud break, the growing young leaves were probably more influenced by temperature and Rain that permitted the progressive recovery of the leaf vegetative development delay.

However, the underlying mechanism through which solar radiation affects spring phenological events (bud break, leaf flushing) remains poorly understood in temperate woody species

\section{(Brelsford and Robson, 2018).}

In particular, the effect that spectral composition has on the timing of bud burst and leaf out in tree species has been studied much less than that of photoperiod, even though light composition changes with the time of year, day length, latitude, cloud cover and other factors that alter the ratio of direct to diffuse solar radiation (Hughes et al., 1984; Johnson et al., 1967; Smith, 1982; Urban et al., 2007).

Recent studies have found a negative correlation between heat requirement and insolation sum during dormancy, showing that years with more insolation tend to have earlier leaf flushing (in 
response to the reduced heat requirement). This evidence could suggest that the amount of insolation during dormancy may influence the heat requirement for leaf flushing, although the impact is species specific (Fu et al., 2015).

As reported in literature, light may be considered indispensable for mobilization of the carbohydrate reserves necessary for bud burst. Some experiments showed that bud burst was accompanied by a strong increase in the quantities of sucrose in buds originating from the breakdown of bud starch reserves (Girault et al., 2010). The same experiments showed that this mobilization of bud and stem reserves required light, and in fact, in darkness, no increase in the quantities of sucrose in the bud and its bearing node were observed (Smith and Stitt, 2007); such photocontrol of the genes involved in the sugar mobilization processes during bud burst therefore seems plausible (Girault et al., 2008).

\section{References}

Aguilera F, Fornaciari M, Ruiz-Valenzuela L, Galán C, Msallem M, Ben Dhiab A, de la Díaz Guardia C, Trigo MM, Bonofiglio T, Orlandi F, 2014: Phenological models to predict the main flowering phases of olive (Olea europaea L.) along a latitudinal and longitudinal gradient across the Mediterranean region. International Journal of Biometeorology, DOI: 10.1007/s00484-014-0876-7

Bergant K, Kajfez-Bogataj L, Crepinsek Z, 2002: Statistical downscaling of GCM simulated average monthly air temperature to the beginning of flowering of dandelion (Taraxacum officinale) in Slovenia. International Journal of Biometeorology 46, 22-32.

Brelsford CC, Robson TM, 2018: Blue light advances bud burst in branches of three deciduous tree species under short-day conditions. Trees 32, 1157-1164. DOI: $10.1007 / \mathrm{s} 00468-018-1684-1$

Chmielewski FM, Müller A, Bruns E, 2004: Climate changes and trends in phenology of fruit trees and field crops in Germany 1961-2000. Agricultural and Forest Meteorology 121, 69-78.

Chmielewski FM, Rötzer T, 2001: Response of tree phenology to climate change across Europe. Agricultural and Forest Meteorology 108, 101-112.

Chuine I, Morin X, Bugmann H, 2010: Warming, photoperiods, and tree phenology. Science 329, 277-278.

Fu YH, Piao S, Vitasse Y, Zhao H, De Boeck HJ, Liu Q, Yang H, Weber U, Hänninen H, Janssens IA, 2015: Increased heat requirement for leaf flushing in temperate woody species over 1980-2012: effects of chilling, precipitation and insolation. Global change biology 21(7), 2687-2697.

Girault T, Bergougnoux V, Combes D, Viémont JD, Leduc N, 2008: Light controls shoot meristem organogenic activity and leaf primordia growth during bud burst in Rosa sp. Plant, Cell \& Environment 31, 1534-1544.

Girault T, Abidi F, Sigogne M, Pelleschi-Travier S, Boumaza R, Sakr S, Leduc N, 2010: Sugars are under light control during bud burst in Rosa sp. Plant, Cell \& Environment 33, 1339-1350. DOI: $10.1111 / j .1365-3040.2010 .02152 . x$

Gordo O, Sanz JJ, 2010: Impact of climate change on plant phenology in Mediterranean ecosystems. Global Change Biology 16, 1082-1106.

Hughes JE, Morgan DC, Lambton PA, Black CR, Smith H, 1984: Photoperiodic time signals during twilight. Plant, Cell
\& Environment 7, 269-277.

Johnson TB, Salisbury FB, Connor GI, 1967: Ratio of blue to red light: a brief increase following sunset. Science 155, 1663-1665.

Kramer K, 1994: Selecting a model to predict the onset of growth of Fagus sylvatica. Journal of Applied Ecology 31, 172-181.

Larcher W, 2003: Physiological Plant Ecology: Ecophysiology and Stress Physiology of Functional Groups. Springer, 513 pp.

Meals DW, Spooner J, Dressing SA, Harcum JB, 2011: Statistical analysis for monotonic trends, Tech Notes 6, November 2011. Developed for U.S. Environmental Protection Agency by Tetra Tech, Inc., Fairfax, VA, 23 p. Available online at https:// www.epa.gov/polluted-runoff-nonpointsource-pollution/ nonpoint-source-monitoringtechnical-notes.

Menzel A, Sparks TH, Estrella N, Koch E, Aasa A, Ahas $\mathrm{R}$, Alm-Kübler K, Bissolli $\mathrm{P}$, Braslavská O, Agrita B, Chmielewski FM, Crepinsek Z, Curnel Y, Dahl Å, Defila C, Donnelly A, Filella Y, Jatczak K, Måge F, Mestre A, Nordli $\varnothing$, Peñuelas J, Pirinen P, Remišová V, Scheifinger H, Striz M, Susnik A, Van Vliet AJH, Wielgolaski FE, Zach S, Zust A, 2006: European phenological response to climate change matches the warming pattern. Global Change Biology 12, 1969-1976.

Orlandi F, Bonofiglio T, Ruga L, Sgromo C, Romano B, Fornaciari M, 2007: Phenological investigations of different winter-deciduous species growing under Mediterranean conditions. Annals of Forest Science 64, 557-568.

Orlandi F, Ruga L, Bonofiglio T, Romano B, Fornaciari M, 2014: Fifteen-year phenological plant species and meteorological trends in central Italy. International Journal of Biometeorology 58, 661-667.

Pohlert T, 2015: Trend: Non-Parametric Trend Tests and Change-Point Detection, $\mathrm{R}$ package version 0.0.1. DOI: 10.13140/RG.2.1.2633.4243

Saska MM, Kuzovkina YA, 2010: Phenological stages of willow (Salix). Annals of Applied Biology 156, 431-437.

Schleip C, Rutishauser T, Luterbacher J, Menzel A, 2008: Time series modeling and central European temperature impact assessment of phenological records over the last 250 years. Journal of Geophysical Research 113, G04026, DOI: 10.1029/2007JG000646

Schnelle F, Volkert E, 1964: Internationale Phaenologische Garten. Agricultural Meteorology 1, 22-29.

Sirois A, 1998: A brief and biased overview of time series analysis or how to find that evasive trend. In WMO report No. 133: WMO/EMEP workshop on Advanced Statistical methods and their application to air quality data sets (Helsinki, 14-18 September 1998).

Smith H, 1982: Light quality, photoperception, and plant strategy. Annual Review of Plant Physiology 33, 481-518.

Smith AM, Stitt M, 2007: Coordination of carbon supply and plant growth. Plant, Cell \& Environment 30, 1126-1149.

Urban O, Janouš D, Acosta M, Czerný R, Markova I, Navratil M, Pavelka M, Pokorný R, Šprtová M, Zhang R, Špunda V, 2007: Ecophysiological controls over the net ecosystem exchange of mountain spruce stand. Comparison of the response in direct vs. diffuse solar radiation. Global Change Biology 13, 157-168.

Waldau T, Chmielewski FM, 2018: Spatial and temporal changes of spring temperature, thermal growing season and spring phenology in Germany 1951-2015. Meteorologische Zeitschrift 27(4), 335-342. DOI: 10.1127/metz/2018/0923 